\title{
Retraction Note: A neural network-based rainfall trend in plain areas and a personalized French learning system
}

\author{
Guangzhi Xiao'
}

Published online: 6 December 2021

C) Saudi Society for Geosciences 2021

Retraction Note: Arabian Journal of Geosciences (2021) 14: 1209

https://doi.org/10.1007/s12517-021-07419-2

The Editor-in-Chief and the Publisher have retracted this article because the content of this article is nonsensical. The peer review process was not carried out in accordance with the Publisher's peer review policy. The author has not responded to correspondence regarding this retraction.

The original article can be found online at https://doi.org/10.1007/ s12517-021-07419-2

Guangzhi Xiao

xiaoguangzhi2011@163.com

1 School of Foreign Languages, Sias University, Xinzheng 451150, Henan, China 